\title{
Effects of tidal currents on meiofauna densities in vegetated salt marsh sediments
}

\author{
J. W. Fleeger, G. T. Chandler, G. R. Fitzhugh and F. E. Phillips \\ Department of Zoology and Physiology, Louisiana State University, Baton Rouge, Louisiana 70803, USA
}

\begin{abstract}
The effect of tidal currents on densities of mud-dwelling meiofauna in natural vegetated sediments is unknown. To test for an effect, replicate core samples were collected at low (air exposed), flood, slack high and ebb tide from an intertidal Spartina alterniflora marsh. Emergence traps were set to determine if benthic species occur in suspension. Meiofauna were present but not abundant in all emergence traps. For most taxa, highest sediment densities were at low tide, and lowest densities were on the ebbing tide when current velocities were highest. Densities were significantly lower on the ebbing tide compared to low tide for nematodes, copepod nauplii and for 3 of the 6 most abundant copepod species. Tidal currents passing among $S$. alterniflora culms are sufficient to affect meiofauna densities by suspending individuals above vegetated sediments. However, behavior and life-style of individual copepod species must determine which species will be affected.
\end{abstract}

\section{INTRODUCTION}

Several recent studies have shown that meiofauna can no longer be considered as holobenthic infauna existing only among sediment particles (Bell and Sherman, 1980; Hagerman and Rieger, 1981; Palmer and Brandt, 1981; Chandler and Fleeger, 1983). This is especially true in muddy substrates where fauna lack adhesive capabilities, and where sediments and their fauna are easily suspended by water movement. Harpacticoid copepods seem particularly vulnerable to suspension by tidal currents as several species are active on sediment surfaces (Palmer, 1984) or are epibenthic or hyperbenthic, i.e. associated with near bottom water and superficial sediments (Alldredge and King, 1980; Sibert, 1981).

Meiofauna are abundant in vegetated, seagrass systems (Bell, 1979; Fleeger, 1980); however, densities in nearby vegetated and non-vegetated areas may differ (Decho, 1982; Osenga and Coull, 1983). One factor which could account for this variation is the change in speed and flow characteristics of tidal currents upon entering grass beds. Abundant grass culms block laminar water flow and reduce sheer stress by establishing a skimming flow, thus allowing deposition of suspended sediment (Eckman et al., 1981; Fonseca et al., 1982). Compared to non-vegetated areas, this effect on currents may influence local suspension and redeposition of meiofauna, causing an increased recruitment of larvae or suspended adults (Eckman, 1983). However, empirical studies of the effects of tidal currents on densities of mud-dwelling meiofauna in natural vegetated sediments have not been conducted.

The purpose of this investigation was to determine if significant variations in meiofauna density in Spartina alterniflora sediments occur with variations in tidal current intensity. Meiofauna in salt marshes are indeed sediment-dwellers, lacking morphological capabilities of clinging or grasping to Spartina culms (Coull et al., 1979). To this end, nematodes and copepod species were sampled in Louisiana salt marsh sediments at 4 stages of a diurnal tide, and emergence traps were used to determine if these same benthic species entered the water column during times of high current flow.

\section{METHODS}

The study was conducted on a cord-grass covered, streamside levee of a Spartina alterniflora marsh much like that described by Fleeger and Chandler (1983), but located near the Port Fourchon Marine Laboratory $\left(29^{\circ} 10^{\prime} \mathrm{N}, 90^{\circ} 10^{\prime} \mathrm{W}\right)$, La Fourche Parish Louisiana, USA. Five similar, adjoining plots $(2 \times 4 \mathrm{~m})$ were sampled at low tide on July 18,1982 , while the sediment was exposed to air. Four replicate cores $(2.61 \mathrm{~cm}$ diameter) were taken randomly between $S$. alterniflora 
culms within each plot. Equal numbers of cores were again collected at $6 \mathrm{~h}$ intervals on the subsequent flooding, slack high, and ebbing tides. At the time of each sampling, current velocities in the adjacent tidal bayou (about $3 \mathrm{~m}$ from the plots) were measured by timing the movement of a slightly buoyant orange over a $5 \mathrm{~m}$ distance with a stop watch. We expect that tidal velocities between the plants vary relative to the bayou over the tidal stages, and will use these velocities only as an indication of the current intensity in the marsh. All cores were frozen in the field in liquid nitrogen, and stored frozen in the laboratory until cut at $2 \mathrm{~cm}$ intervals to a depth of $6 \mathrm{~cm}$ with a coping saw. Each individual core fraction was stained with Rose Bengal and fixed in $10 \%$ buffered formalin. Samples were extracted by flotation in LUDOX AM (Fleeger and Chandler, 1983), and nematodes and copepods were enumerated.

Vertical emergence of benthic, epibenthic and hyperbenthic fauna was estimated during flooding and ebbing tides. Ten emergence traps were randomly placed, 2 per plot, among the 5 plots and suspended $1 \mathrm{~cm}$ above the sediment surface. The emergence traps were composed of an inverted funnel surrounded by a polyethylene bottle. The funnels measure $6 \mathrm{~cm}$ diameter at the mouth with a vertical stem of $8 \mathrm{~cm}$ through which the animals must traverse before capture. Thus $9 \mathrm{~cm}$ of water must cover the marsh surface before the traps can collect suspended fauna. We estimate that water of this or greater height covered the marsh for $10 \mathrm{~h}$ during flooding to ebbing tide. To minimize trap effects on the sediments, traps were suspended on nylon twine beneath tripods made from doweling of the same diameter as the surrounding Spartina alterniflora culms. Traps were set at low tide, 8:40 p.m., and their contents were collected at mid slack high tide, 11:00 a.m., reset and collected again at low tide, $4: 30$ p.rn.

Statistical analysis of core replicates was conducted by 2-way MANOVA comparing meiofauna densities at each stage of the tide from each plot and tide-by-plot interaction. One-way MANOVA was used to analyze densities of emergence trap fauna from flooding and ebbing tides. If MANOVA indicated significant tidal effects, univariate ANOVAs were conducted to test for tidal effects on individual, abundant taxa. Data were $\log _{10}(x+1)$ transformed to meet the assumptions of normality. Where significance was indicated by ANOVA, Duncan's Multiple Range test and Scheffe's test were applied to obtain all pairwise comparisons among sample means for each taxon. Analysis was by means of the SAS General Linear Models procedure (Helwig and Council, 1979). ANOVAs were calculated on data from each core depth as well as on the $0-6 \mathrm{~cm}$ combined density for each core.

\section{RESULTS}

The depth profile and taxonomic composition of meiofauna found in this Louisiana salt marsh are similar to those reported from other muddy estuarine areas (McIntyre, 1969; Coull, 1973). Approximately $90 \%$ of the copepods and nauplii, and $62 \%$ of the nematodes were found in the 0 to $2 \mathrm{~cm}$ fraction. Nematodes probably occurred below the $6 \mathrm{~cm}$ depth level, as evidenced by a slow reduction in density with depth (see also Sikora and Sikora, 1982).

Densities of several taxa varied with tidal state (Fig. 1 to 3). Densities were highest for most taxa at low tide and lowest with the ebbing tide. MANOVA demonstrates significant variation among tides $(P=0.03)$ and among plots $(\mathrm{P}=0.0001)$. However, no significant effect was noted for the tide-by-plot interaction ( $\mathrm{P}=$ $0.3)$. Nematodes, copepods, nauplii and the copepod species Enhydrosoma woodini Thistle, Stenhelia (Delavalia) bifidia Coull and Nannopus palustris Brady

BLOCK CHART OF MEAN

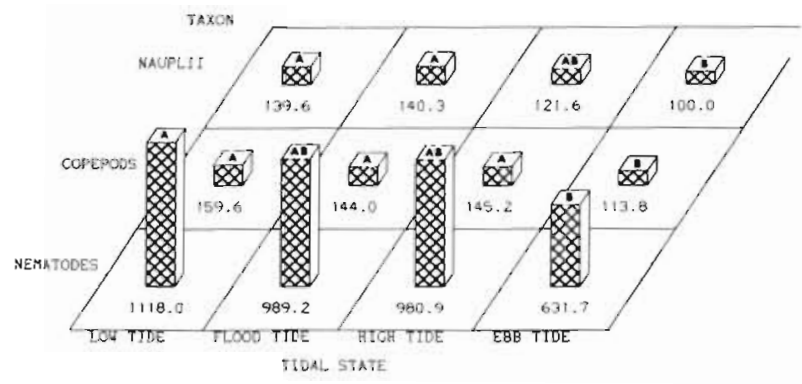

Fig. 1. Mean density $10 \mathrm{~cm}^{-2}$ of meiofauna major taxa at various tidal states. Letters: results of Duncan's Multiple Range Test; columns with the same letter designation are not significantly different

BLOCK CHART OF MEASS

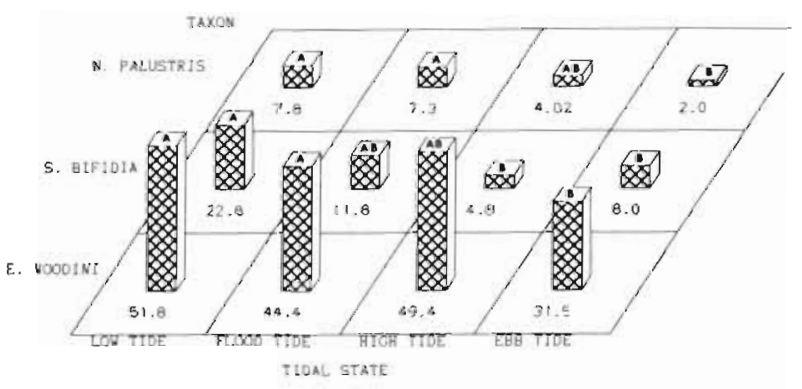

Fig. 2. Mean density $10 \mathrm{~cm}^{-2}$ of the copepod species Enhydrosoma woodini, Stenhelia (D.) bifidia and Nannopus palustris at various tidal states. See Fig. 1 for explanation of letter designations 
BLOCK CHART OF MEANS

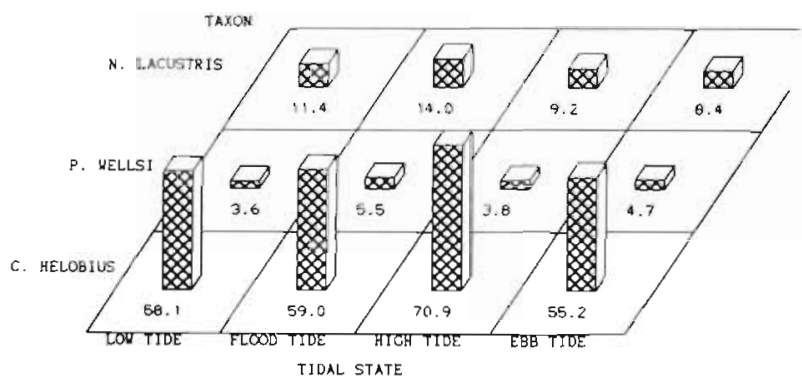

Fig. 3. Mean density $10 \mathrm{~cm}^{-2}$ of the copepod species Cletocamptus helobius, Pseudostenhelia wellsi and Nitocra lacustris at various tidal states. See Fig. 1 for explanation of letter designations

varied by as much as $30 \%$ over the 4 tidal stages. ANOVA indicates that tidal variation was significant for the aforementioned taxa but not significant for the copepod species Pseudostenhelia wellsi Coull and Fleeger, Cletocamptus helobius Fleeger and Nitocra lacustris (Schmankevitsch). In some taxa, e.g. E. woodini, among-plot differences in density occurred indicating spatial variability within the study site. The variation reported here is that for the density summed across all depths, 0 to $6 \mathrm{~cm}$. ANOVA conducted on each depth separately (i.e. from the 0 to 2,2 to 4 and
4 to $6 \mathrm{~cm}$ depths) shows equivalent trends for density variation with tides only at the 0 to $2 \mathrm{~cm}$ depth. In no instance did densities from 2 to 4 or 4 to $6 \mathrm{~cm}$ significantly vary with the tide for any taxon, indicating no change in the 2 to $6 \mathrm{~cm}$ vertical profile throughout a tidal cycle.

Duncan's Multiple Range tests (Fig. 1 to 3 ) show that these density differences between low tide and ebb tide were significant for nematodes, copepod nauplii and the harpacticoid species Enhydrosoma woodini, Stenhelia (D.) bifidia and Nannopus palustris. Generally densities with the flooding tide and at slack high did not differ from either low or ebb tide values. Scheffe's test, however, was more conservative, with significant differences occurring only with $S$. (D.) bifidia and $N$. palustris between low and ebb tide. Current velocities were highest $\left(15 \mathrm{~cm} \mathrm{~s}^{-1}\right)$ with the ebbing tide, low $\left(4 \mathrm{~cm} \mathrm{~s}^{-1}\right)$ with the flooding tide, and 0 at slack high in the bayou adjacent to the marsh. These trends are consistent with the hypothesis that high current velocities, even in a grass bed, reduce meiofauna densities in muddy sediments.

Emergence traps collected a variety of organisms; however, planktonic forms predominated. Most abundant were polychaete larvae, crab larvae, copepod nauplii, and 2 pelagic copepods, Acartia tonsa and Oithona colcarva (Table 1). However, every trap contained taxa traditionally recognized as meiobenthic. Nematodes occurred in 11 of the 20 traps; harpacticoid

Table 1. Summary of emergence trap captures. Abundance: mean number of individuals collected; frequency: number of occurrences in 10 emergence traps

\begin{tabular}{|c|c|c|c|c|}
\hline \multirow[t]{2}{*}{ TAXON } & \multicolumn{2}{|c|}{ FLOOD } & \multicolumn{2}{|c|}{ EBB } \\
\hline & Abundance & Frequency & Abundance & Frequency \\
\hline \multicolumn{5}{|l|}{ Planktonic } \\
\hline Polychaete larvae ${ }^{\circ}$ & 103.0 & 10 & 3.3 & 8 \\
\hline Crab larvae & 23.4 & 10 & 27.3 & 9 \\
\hline Copepod nauplii & 358.0 & 10 & 50.9 & 10 \\
\hline \multicolumn{5}{|l|}{ Copepods } \\
\hline Acartia tonsa & 329.0 & 10 & 619.0 & 10 \\
\hline Oithona colcarva & 77.0 & 10 & 12.8 & 10 \\
\hline \multicolumn{5}{|l|}{ Benthic } \\
\hline Nematodes" & 5.2 & 9 & 0.4 & 2 \\
\hline \multicolumn{5}{|l|}{ Copepods } \\
\hline Enhydrosoma woodini & 0.6 & 5 & 0.6 & 3 \\
\hline Cletocamptus helobius & 0.5 & 4 & 0.8 & 4 \\
\hline Pseudostenhelia wellsi & 0.2 & 2 & - & 0 \\
\hline Stenhelia (D.) bifidia & 0.4 & 2 & - & 0 \\
\hline Nitocra lacustris & 0.4 & 4 & 0.1 & 1 \\
\hline Nannopus palustris & - & 0 & - & 0 \\
\hline Halicyclops coulli ${ }^{\circ}$ & 37.0 & 10 & 6.8 & 7 \\
\hline Scottolana canadensis ${ }^{*}$ & 5.0 & 8 & 0.3 & 3 \\
\hline
\end{tabular}


copepods were found in all traps. Fifteen copepod species were found in the emergence traps compared to 12 found in the sediment cores. Of those present in sediment cores, only Nannopus palustris was not found in at least 1 trap.

Tidal stage had a significant (MANOVA test, $\mathrm{P}=$ 0.03 ) overall effect on trap densities. ANOVA was conducted on each of the 15 most abundant taxa, and showed variation in densities between flood and ebb tide in 9 taxa (Table 1). For all 9 taxa, more individuals were present in traps set on the flooding rather than ebbing tide.

\section{DISCUSSION}

Densities of several meiofauna taxa from these vegetated marsh sediments were highest with no water on the sediment surface and lowest at the time of highest tidal currents at ebb tide. Meiofauna vertical profiles in cores did not vary significantly with tidal state indicating that vertical migration did not take place. Furthemore, meiofauna were in the water column as evidenced by emergence traps which collected nematodes and 11 of 12 copepod species found also in core samples. Each emergence trap contained taxa traditionally considered benthic even though the traps are small and sampled smaller volumes of water than traps commonly used in most field studies (Youngbluth, 1982). Our data support Palmer and Brandt's (1981) conclusion that reduced sediment densities during high flow conditions are due to suspension of meiofauna, and show that tidal flushing may reduce meiofauna densities in grass bed sediments as well as in non-vegetated areas.

It is not possible from this study to estimate the overall significance of tidal suspension on salt marsh meiofauna. The tidal height ( $+0.53 \mathrm{~m}$ on July 18) was unusually high for the Louisiana coast, suggesting that ebb tidal currents were probably stronger than usual on the day of collection. We cannot determine the likelihood of net import or export of marsh meiofauna to or from vegetated areas even though Louisiana marshes are known to be depositional sedimentary environments (DeLaune et al., 1978), and that grass culms are expected to slow currents and reduce flushing (Eckman, 1983). Little evidence is available to support high rates of migration between marsh and subtidal areas. Coull et al. (1979) have found that copepod species tend to be either subtidal or intertidal and only Microarthridion littorale is found across the entire gradient in South Carolina. Palmer (1980), however, could not support large scale mixing between subtidal and intertidal marsh populations of $M$. littorale. Meiofauna, even if suspended in the water column, are probably not capable of long distance dispersal under near normal current conditions, and it seems likely that most animals return to the sediments before being flushed or exported from the marsh.

The emergence traps collected a diversity of larval and adult species. Zooplankton, all typically associated with salt marsh creeks and bayous (Lonsdale and Coull, 1977), predominated in the traps and probably move in and out of the marsh with the tide. Generally higher numbers of individuals were present in traps set on the flooding tide (night sample). This would be expected for emergent forms, for species entering the marsh with the tide and for species which undergo vertical migration such as Oithona colcarva (Ohlhurst, 1982). For traditionally recognized benthic species, slightly higher numbers and frequencies of occurrence were also found in the flood as compared to the ebb tide traps. This was unexpected because highest current speeds were on the ebb tide when lowest sediment densities occurred for several harpacticoid species, and meiofauna do not appear to respond to day-night cues for emergence (Palmer, 1984). In addition, the emergence traps may not have adequately sampled suspended benthos because each funnel mouth was about $9 \mathrm{~cm}$ above the sediment surface. Palmer (1984) has shown that most meiobenthic copepods swept into the water column orient and swim downward and quickly burrow into the sediment. Thus individuals passively flushed into the water column may have been able to stay well below the mouths of the traps used in our field experiment.

Of the six harpacticoid species abundant enough to analyze, 3 species (Cletocamptus helobius, Nitocra lacustris and Pseudostenhelia wellsi) showed no variation associated with tidal currents. Certainly there may be differences in natural history between copepod species which would account for these differences. Our data suggest that meiofauna passively leave the sediment because lowest densities occurred with highest current flows. Species unaffected by tidal movement may be deeper-dwelling burrowers (below the depth at which resuspension may occur) or may have a lifestyle which otherwise protects them from passive suspension under normal current conditions (Palmer, 1984). Recent observations of copepods at the benthic boundary layer in laboratory sediments reveal that $P$. wellsi is in fact a tube-dweller, living in mucoid tunnels extending to $0.4 \mathrm{~cm}$ in the sediment (Chandler and Fleeger, 1984). The tube-dwelling life-style of $P$. wellsi may insulate it from current induced suspension. More of the natural histories of meiofauna must be known before it is possible to fully interpret findings such as those reported here and by Palmer and Brandt (1981). Nevertheless, meiofauna researchers working in vegetated as well as non-vegetated sedi- 
ments will need to be aware of tidal induced variability when estimating densities.

Acknowledgements. We thank B. Hendrix and S. Hilliard for sorting samples and A. Decho for commenting on a draft of the manuscript. Discussions with $M$. Palmer improved the interpretation of this work.

\section{LITERATURE CITED}

Alldredge, A. L., King, J. M. (1980). Effects of moonlight on the vertical migration patterns of demersal zooplankton. J. exp. mar. Biol. Ecol. 44: 133-156

Bell, S. S. (1979). Short- and long-term variation in a high marsh meiofauna community. Estuar. coast. mar. Sci. 9: 331-350

Bell, S. S., Sherman, K. M. (1980). A field investigation of meiofaunal dispersal: tidal resuspension and implications. Mar. Ecol. Prog. Ser. 3: 245-249

Chandler, G. T., Fleeger, J. W. (1983). Meiofaunal colonization of azoic estuarine sediment in Louisiana: mechanisms of dispersal. J. exp. mar. Biol. Ecol. 69: 175-188

Chandler, G. T., Fleeger, J. W. (1984). Tube-building by a marine meiobenthic harpacticoid copepod. Mar. Biol., in press

Coull, B. C. (1973). Estuarine meiofauna: A review, trophic relationships and microbial interactions. In: Stevenson, $\mathrm{L}$. H., Colwell, R. R. (ed.) Estuarine microbial ecology. University of South Carolina Press, Columbia, p. 499-511

Coull, B. C., Bell, S. S., Savory, A. M., Dudley, B. W. (1979). Zonation of meiobenthic copepods in a southeastem United States salt marsh. Estuar. coast. mar. Sci. 9: $181-188$

Decho, A. (1982). A comparative study of the meiofaunal community structure of a subtropical seagrass bed (Thalassia testudinum) and an adjacent barren sand area. M. S. thesis, Ohio University, Athens

DeLaune, R. D., Patrick, W. H., Buresh, R. J. (1978). Sedimentation rates determined by ${ }^{137} \mathrm{Cs}$ dating in a rapidly accreting salt marsh. Nature, Lond. 275: 532-533

Eckman, J. E. (1983). Hydrodynamic processes affecting benthic recruitment. Limnol. Oceanogr. 28: 241-257

Eckman, J. E., Nowell, A. R. M., Jumars, P. A. (1981). Sedi- ment destabilization by animal tubes. J. mar. Res. 39; 361-374

Fleeger, J. W. (1980). Community structure of an estuarine meiobenthic copepod assemblage. Estuar. coast. mar. Sci 10: $107-117$

Fleeger, J. W., Chandler, G. T. (1983). Meiofauna responses to an experimental oil spill in a Louisiana salt marsh. Mar. Ecol. Prog. Ser. 11: 257-264

Fonseca, M. S., Fisher, J. S., Zieman, J. C., Thayer, G. W. (1982). Influence of the seagrass, Zostera marina L., on current flow. Estuar. coast. Shelf Sci. 15: 351-364

Hagerman, G. M., Rieger, R. M. (1981). Dispersal of benthic meiofauna by wave and current action in Bogue Sound North Carolina, U.S.A. P.S.Z.N.I: Mar. Ecol. 2: 245-270

Helwig, J. T., Council, K. A. (ed.) (1979). SAS users guide, 1979. SAS Institute Inc., Raleigh, North Carolina

Londsdale, D. J., Coull, B. C. (1977). Composition and seasonality of zooplankton of North Inlet, South Carolina. Chesapeake Sci. 18: 272-283

McIntyre, A. D. (1969). Ecology of marine meiobenthos. Biol. Rev. 44: 245-290

Ohlhurst, S. L. (1982). Diel migration patterns of demersal reef zooplankton. J. exp. mar. Biol. Ecol. 60: 1-15

Palmer, M. A. (1980). Variation in life-history patterns between intertidal and subtidal populations of the meiobenthic copepod Microarthridion littorale. Mar. Biol. 60: 159-165

Palmer, M. A. (1984). Invertebrate drift: behavioral experiments with intertidal meiobenthos. Mar. behav. Physiol. 10: $235-253$

Palmer, M. A., Brandt, R. R. (1981). Tidal variation in sediment densities of marine benthic copepods. Mar. Ecol. Prog. Ser. 4: 207-212

Osenga, G. A., Coull, B. C. (1983). Spartina alterniflora (Loisel) root structure and meiofaunal abundance. J. exp. mar. Biol. Ecol. 67: 221-225

Sibert, J. R. (1981). Intertidal hyperbenthic populations in the Nanaimo Estuary. Mar. Biol. 46: 259-265

Sikora, W. B., Sikora, J. P. (1982). Ecological implications of the vertical distribution of meiofauna in salt marsh sediments. In: Kennedy, V. S. (ed.) Estuarine comparisons. Academic Press, New York, p. 269-282

Youngbluth, M. J. (1982). Sampling demersal zooplankton: a comparison of field collections using three different emergence traps. J. exp. mar. Biol. Ecol. 61: 111-124 